ORIGINAL ARTICLE

\title{
Values and predictive factors for Success of Methotrexate Therapy in Medical Management of Ectopic Pregnancy
}

\author{
Mohamed El-Bakry Lashin ${ }^{\text {I, Mohamed Ali Alabiad }}{ }^{\text {II }}$, Walid A Abdelsalam ${ }^{\text {I }}$ \\ I: Department of Gynecology and Obstetrics, Zagazig University Faculty of Medicine, Zagazig University Egypt \\ II: Department of Pathology, Zagazig University Faculty of Medicine, Zagazig University Egypt
}

*Corresponding author:

Mohamed Ali Alabiad

Lecturer of Pathology,

Faculty of Medicine,

Zagazig University

Email; alabiad@zu.edu.eg

Submit Date: 2020-07-21

Revise Date: 2020-08-07

Accept Date: 2020-08-18

\section{ABSTRACT}

Background: Using Methotrexate as an option for medical treatment of ectopic pregnancies has been suggested since 1982. Studies regarding the dose, number of doses of methotrexate and the predictive factors of degree of success of methotrexate in the medical management of ectopic pregnancy are limited. Aim of the present article were; to assess the predictive factors of success and efficacy of methotrexate therapy and to assess the value and efficacy of using lower dose of methotrexate and the suitable number of doses for medical management of ectopic pregnancy. Methods: we included 100 patients with ectopic tubal pregnancy that were given Methotrexate dosage $1 \mathrm{mg} / \mathrm{kg}$ which was injected intramuscular. After the first injection we asked the patients to return on the $4^{\text {th }}$ day then on the $7^{\text {th }}$ day to test the levels of hCG. In case of reduction of the level of $\beta$-hCG less than $15 \%$ on $4^{\text {th }}$ and $7^{\text {th }}$ days, patients were given the second methotrexate dose of $1 \mathrm{mg} / \mathrm{kg}$ which was also injected intramuscular. We followed patients until achieving $\beta$-hCG target level $(<15 \mathrm{mIU} / \mathrm{mL})$ then completely negative values. We assessed rates and predictive factors for success or failure of methotrexate therapy. Results: of the included 100 patients, 15 patients needed surgical management at the end of treatment, with a success rate of medical Methotrexate therapy of $85 \%$.The pretreatment predictive factors of failure of medical treatment are; presence of a pretreatment adnexal mass $(\mathrm{p}=0.040)$, presence of pain $(\mathrm{p}=0.039)$, metrorrhagia $(\mathrm{p}=0.023)$, or hemoperitoneum $(\mathrm{p}=0.002)$. Base line pretreatment hCG levels was the most important predictive factor of therapy success $(p=0.002)$. Conclusions: methotrexate in a single dose or two doses could effectively treat ectopic pregnancy with fewer side effects providing that base line hCG level < 5000 IU/L in hemodynamically stable young patients with no liver or kidney problems with a higher success rate.

Keywords: ectopic pregnancy, medical therapy, methotrexate, $\beta$-hCG

\section{INTRODUCTION}

$\mathrm{E}$ ctopic pregnancy forms $2 \%$ of all pregnancies [1], but its incidence increased to $5 \%$ in pregnant patients with assisted reproductive techniques [2]. The number of cases died from disturbed ectopic pregnancy has been decreased, but it still forms about $6 \%$ of all maternal fatality [3]. Early diagnosis of ectopic pregnancy allowed a better medical treatment and in addition to liability of avoiding surgery in some cases [4, 5]. Using Methotrexate (MTX) as an option for medical treatment of ectopic pregnancies has been suggested by Tanaka et al., since 1982 [6]. Methotrexate is an inhibiting factor of most phases of the cell cycle, particularly the $S$ phase and it has a strong effect on rapidly growing cells mainly the trophoblasts [7]. Moreover 
Methotrexate has been associated with many adverse effects due to its action on cell cycle and cell renewal system. Up to $35 \%$ of patients experiences methotrexate related side effects which were found to be decreased in incidence and severity with using a single dose protocol [8]. There is no reached consensus about the threshold of human Chorionic Gonadotropin (hCG) above which the use of methotrexate is not recommended [1].

Studies regarding the dose, number of doses of methotrexate and the predictive factors of degree of success of methotrexate in the medical management of ectopic pregnancy are limited.

Aim of the present article were; to assess the predictive factors of success and efficacy of methotrexate therapy and to assess the value and efficacy of using lower dose of methotrexate and the suitable number of doses for medical management of ectopic pregnancy.

\section{METHODS}

This is a prospective randomized study which has been performed in Gynecology and Obstetrics Department, Faculty of Medicine, Zagazig University in the period from March 2016 to March 2020. Patients were hospitalized due to tubal ectopic pregnancy.

Inclusion criteria:

Patients with a sure diagnosis of ectopic pregnancy who were hemodynamically stable without hepatic or renal impairment, patients without free fluid in the pelvis as detected by trans-vaginal ultrasound and there is absence of embryonic cardiac activity

Exclusion criteria:

Patients with a diagnosis of cervical, ovarian and scar pregnancy were excluded. Patients with renal or hepatic dysfunction, patients with anemia or leucopenia were excluded from the study. Patients that we lost their follow-up data or experiences serious complications from methotrexate therapy were excluded.

After application of inclusion criteria of the study we included 100 patients with ectopic pregnancy who were accepted to start medical treatment using methotrexate therapy regardless $\beta$-hCG baseline levels after signing written informed consents were obtained from all patients and local ethical committee approval. Collected data from patients files and follow-up records included; patients demographics, history of occurrence of previous ectopic pregnancy, history of previous gynecological surgeries, using assisted reproductive techniques, transvaginal ultrasound findings as (presence of adnexal mass, or presence of free fluid), levels of $\beta$-hCG, results of endometrial biopsy, liver and kidney functions, the dose and number of doses of methotrexate used, and the failure of medical therapy and need for a surgical management.

Methotrexate dosage was $1 \mathrm{mg} / \mathrm{kg}$ which was injected intramuscular after determining the base line levels of hCG at starting therapy (day0) as previously mentioned [4]. After the first injection we asked the patients to return on the $4^{\text {th }}$ day then on the $7^{\text {th }}$ day to test the levels of hCG, and we have performed a trans-vaginal ultrasound as a control in day 7.

In case of reduction of the level of $\beta$-hCG less than $15 \%$ on $4^{\text {th }}$ and $7^{\text {th }}$ days, patients were given the second methotrexate dose of $1 \mathrm{mg} / \mathrm{kg}$ which was also injected intramuscular. The maximum allowed dose of methotrexate in the present study are 2 doses. We evaluated response to medical treatment, needing second dose or the failure of medical therapy and the need for surgical management were evaluated in all included patients.

We followed patients who were responding to medical therapy whether the first or second dose weekly until achieving $\beta$-hCG target level $(<15 \mathrm{mIU} / \mathrm{mL})$ then completely negative values $[1,5,9]$.

Failure of medical therapy by methotrexate is denoted by occurrence of persistent or increasing pelvic pain, an increasing the adnexal mass size using trans-vaginal ultrasound or suboptimal reduction in $\mathrm{hCG}$ levels [4].

Surgical intervention was depending on general patient condition, the tube condition during laparoscopic examination and preference of the patient. Performed surgical procedures included salpingotomy as a conservative approach or 
radical surgical intervention by performing salpingectomy.

We analyze all findings from treatment responsive and unresponsive patients to assess predictive factors for success or failure of methotrexate therapy.

We obtained a written informed consent from all included participants, and obtained an approval from research ethical committee of Faculty of Medicine, Zagazig University. The study was performed according to Declaration of Helsinki for studies including human participants.

\section{Statistical analysis}

Statistical analysis has been done using the Statistical Package of the Social Sciences (SPSS) version 23.0. Descriptive data have been expressed as number and frequency or a mean _ standard deviation. We used MannWhitney $U$ test or independent samples t-test whenever applicable, for comparison of biochemical and clinical results of patients responding and not responding to treatment. We used Fisher-Freeman-Halton test to make correlations between rate of success of therapy and patients variables. A $\mathrm{P}$ value of $<0.05$ has been described the statistically significant values.

\section{RESULTS}

We included 100 patients with ectopic pregnancy who have taken Methotrexate therapy, either a single dose or 2 doses.

The detailed correlations between rates of success and failure of medical treatment regarding; pretreatment and post treatment parameters was found in Table1.

At time of initial diagnosis of ectopic pregnancy patients age was about 30 years old and the mean gestational age was about 7 weeks.

After Methotrexate therapy we divided included patients into two groups; first group included patients who responded successfully to medical therapy and second group included patients who did not respond and eventually needed surgical management.

Of the included 100 patients, 15 patients needed surgical management at the end of treatment, with a success rate of medical Methotrexate therapy of $85 \%$.

$10 \%$ of included patients received the second Methotrexate dose. With overall success rate was $90 \%$ in patients having level of $\beta$-hCG $\leq 5000 \mathrm{mIU} / \mathrm{mL}$.

There were no significant correlations between the rate of success of medical treatment, history of previous ectopic pregnancy, history of previous gynecologic surgery, using assisted reproductive techniques, presence of symptoms or fluid in doglas pouch after medical therapy.

The pretreatment predictive factors of failure of medical treatment are; presence of a pretreatment adnexal mass $(\mathrm{p}=0.040)$, presence of pain $(\mathrm{p}=0.039)$, metrorrhagia $(\mathrm{p}=0.023)$, or hemoperitoneum $(\mathrm{p}=0.002)$.

The post-treatment predictive factors of failure of medical treatment are; post injection pain $(p=0.039)$, increasing in the size of the adnexal mass or increasing the levels of $\beta$-hCG.

Performed surgeries were; salpingotomy, salpingectomy and aspiration of hemoperitoneum

When we separated included patients in two groups according to either success or failure of response to medical methotrexate therapy we found that base line pretreatment hCG levels was the most important predictive factor of therapy success.

Women with hCG > $5000 \mathrm{IU} / \mathrm{L}$ showed failure of responding to medical therapy $(\mathrm{p}=0.002)$.

Women with hCG $<2000$ IU/L showed success of Methotrexate therapy. Women with hCG between 2000 and 3000 IU/L showed high failure incidence $(\mathrm{p}=0.041)$. Table 2

Complications from Methotrexate therapy were few and neglected in included patients. 
Table 1. correlations between rate of success and failure of medical treatment regarding; pretreatment and post treatment parameters.

\begin{tabular}{|c|c|c|c|}
\hline & Success & Failure & \multirow[t]{2}{*}{ p } \\
\hline & $\mathrm{N}=85(\%)$ & $\mathrm{N}=15(\%)$ & \\
\hline $\begin{array}{l}\text { Previous ectopic pregnancy } \\
\text { Yes } \\
\text { No }\end{array}$ & $\begin{array}{l}25(29.3) \\
60(70.6)\end{array}$ & $\begin{array}{l}5(33) \\
10(77)\end{array}$ & 1 \\
\hline $\begin{array}{l}\text { Conception } \\
\text { Spontaneous } \\
\text { Ass. Reprod }\end{array}$ & $\begin{array}{l}60(70.6) \\
25(29.3)\end{array}$ & $\begin{array}{l}12(80) \\
3(20)\end{array}$ & 0.311 \\
\hline $\begin{array}{l}\text { Symptoms at diagnosis } \\
\text { Yes } \\
\text { No }\end{array}$ & $\begin{array}{l}65(80) \\
20(20)\end{array}$ & $\begin{array}{l}4(22) \\
11(78)\end{array}$ & 0.49 \\
\hline $\begin{array}{l}\text { Pain at diagnosis } \\
\text { Yes } \\
\text { No }\end{array}$ & $\begin{array}{l}70(85) \\
15(15)\end{array}$ & $\begin{array}{l}11(78) \\
4(22)\end{array}$ & 0.585 \\
\hline $\begin{array}{l}\text { Metrorrhagia at diagnosis } \\
\text { Yes } \\
\text { No }\end{array}$ & $\begin{array}{l}70(85) \\
15(15)\end{array}$ & $\begin{array}{l}12(80) \\
3(20)\end{array}$ & 0.979 \\
\hline $\begin{array}{l}\text { Ultrasound at diagnosis } \\
\text { Mass } \\
\text { PUL }\end{array}$ & $\begin{array}{l}25(29.3) \\
60(70.6)\end{array}$ & $\begin{array}{l}12(80) \\
3(20)\end{array}$ & 0.040 \\
\hline $\begin{array}{l}\text { Fluid in the Douglas pouch } \\
\text { at diagnosis } \\
\text { Yes } \\
\text { No }\end{array}$ & $\begin{array}{l}30(35) \\
55(65)\end{array}$ & $\begin{array}{l}10(77) \\
5(33)\end{array}$ & 0.143 \\
\hline $\begin{array}{l}\text { Pain after MTX } \\
\text { Yes } \\
\text { No }\end{array}$ & $\begin{array}{l}18(17) \\
67(83)\end{array}$ & $\begin{array}{l}13(41) \\
2(23)\end{array}$ & 0.039 \\
\hline $\begin{array}{l}\text { Metrorrhagia after MTX } \\
\text { Yes } \\
\text { No }\end{array}$ & $\begin{array}{l}19(19) \\
66(81)\end{array}$ & $\begin{array}{l}12(80) \\
3(20)\end{array}$ & 0.023 \\
\hline $\begin{array}{l}\text { Fluid in the Douglas pouch } \\
\text { after MTX } \\
\text { Yes } \\
\text { No }\end{array}$ & $\begin{array}{l}20(20) \\
65(80)\end{array}$ & $\begin{array}{l}10(77) \\
5(33)\end{array}$ & 0.002 \\
\hline
\end{tabular}


Table 2. Predictive factors for success of methotrexate medical therapy

\begin{tabular}{|c|c|c|c|}
\hline & Success & Failure & p \\
\hline Maternal age (years) & $30.9 \pm 5.6(21-43)$ & $31.2 \pm 5.0(25-39)$ & 0.808 \\
\hline Gestational age (days) & $40 \pm 13(7-67)$ & $42 \pm 11(27-57)$ & 0.003 \\
\hline Mass size at diagnosis $(\mathrm{cm})$ & $1.4 \pm 0.7(0.3-1.6)$ & $1.9 \pm 0.7(0.7-3.4)$ & 0.311 \\
\hline hCG levels on D0 (IU/L) & $793 \pm 795(60-3563)$ & $\begin{array}{l}3,801 \pm 2,942 \\
9508)\end{array}$ & 0.002 \\
\hline $\begin{array}{l}\text { hCG on D0 (IU/L), categories } \\
<2000 \\
2000-3000 \\
>3000\end{array}$ & $\begin{array}{l}60(93.5) \\
15(71.4) \\
10(12.5)\end{array}$ & $\begin{array}{l}3(6.5) \\
2(28.6) \\
10(87.5)\end{array}$ & 0.041 \\
\hline
\end{tabular}

\section{DISCUSSION}

Surgery was the main management procedure of patients diagnosed with ectopic pregnancy until medical treatment of ectopic pregnancy was hypothesized by Tanaka et al., since 1982 using methotrexate therapy but methotrexate has many side effects [6].

After that, Stovall et al., [10] showed that single dose methotrexate could be safe and effective with fewer side effects than multiple doses.

Anxiety and refusal of treatment by methotrexate by many patients was due to its chemotherapeutic nature and fearing from its side effects, so recent studies were directed towards reducing number of doses and the amount of dose of methotrexate for patients thus reducing side effects and avoiding surgery as possible [2].

In the present study we showed that methotrexate in a single or two doses could effectively treat ectopic pregnancy with fewer side effects providing that base line hCG level $<5000 \mathrm{IU} / \mathrm{L}$ in hemodynamically stable young patients with no liver or kidney problems with a higher success rate. Similarly results and success rates were found by Aydın et al., [2] who evaluated efficacy of using lower doses of methotrexate and Beguin et al., [4] who evaluated the values of using a single dose of methotrexate in management of ectopic pregnancy.

November. 2020 Volume 26 Issue 6
Moreover, it was previously found that methotrexate can be used as a medical therapy for undisturbed ectopic pregnancy patients presented with few manifestations and have hemodynamic stability [11].

Treatment failure has a higher liability of previous ectopic pregnancy or in case of visible gestational sac [9] which was in line with our findings.

Similarly Beguin et al, [4] showed that after a single dose injection $67 \%$ of patients reported a success of treatment. And about $90 \%$ reported a complete success of medical therapy by methotrexate after the second injection. They reported failure of medical treatment and the need for surgical intervention in about $10 \%$ of cases.

Rates of success of methotrexate in management of ectopic pregnancy varied from $64 \%$ to $95 \%$ in most previous reports $[11,12]$

This rate is in line with our results and results of previous studies which reported about 80$78.5 \%$ success rate $[\mathbf{1 , 4 , 9}$.

Additionally, Barbier et al. [13] described a global success rate of $79.1 \%$.

The rate of success of medical treatment by methotrexate therapy in our report was similar to results of previously published studies [2, 14-17]

We showed that $15-20 \%$ of patients who received a single-dose of methotrexate therapy and we have given the second dose in cases of suboptimal reduction in $\beta$-hCG levels between 
day 4 and 7 which was in line with Aydın et al., [2].

In our study about $15 \%$ of patients were not responding to medical treatment and needed a surgical intervention similarly Aydın et al., [2] and Wu et al. [14].

We showed that there are several factors which could predict success or failure of methotrexate therapy as; pretreatment level of $\beta$-hCG level of $\geq 5000 \mathrm{mIU} / \mathrm{mL}$, a moderate to a huge amount of free fluid during transvaginal ultrasound, and a steady elevation in levels of $\beta$-hCG levels after two days of initiating medical therapy, while the rate of success rate was very high in patients with a pretreatment $\beta$-hCG levels between 1900 and $4999 \mathrm{mIU} / \mathrm{mL}$. Our findings were in line with $[\mathbf{2}, \mathbf{4}]$.

Who found that pretreatment levels of is the most important determining factor for treatment response prediction.

$\beta$-hCG levels above $5000 \mathrm{mIU} / \mathrm{mL}$ as a contraindication, of using medical therapy as it is related to a high failure rate and liability for patients deterioration $[\mathbf{1 2}, \mathbf{1 8}]$.

There are many reports which assessed the suitable baseline hCG levels which is predictive of success in methotrexate treatment.

Beguin et al, [4] and Orozco et al. [5] stated that a baseline hCG level < 1000 IU/L and 2439 IU/L respectively is associated with high rate of success.

Orozco et al. [5] showed that the levels of hCG on day 4 was not predictive of treatment results. We showed that failure of medical therapy is due to presence of increasing pelvic pain hemoperitoneum at transvaginal sonography and occurrence of metrorrhagia that was similar to results of [1].

Levin et al. [9] showed that occurrence of pelvic pain after injection of methotrexate is an expected manifestation which is not always denoting complications or failure of therapy.

\section{CONCLUSIONS}

In the current report we showed that methotrexate could be considered a safe medical approach for management of ectopic pregnancy with a suitable base line hCG levels but its efficacy and degree of success is markedly reduced if the base line hCG levels were more than $2439 \mathrm{IU} / \mathrm{L}$ and if hCG is more than $4000 \mathrm{IU} / \mathrm{L}$ it will be associated with a high failure rate.

Moreover we showed that reduction in the levels of hCG on the $4^{\text {th }}$ and $7^{\text {th }}$ days is associated with a higher incidence of therapy success.

We recommend performing a large scale studies for confirming the efficacy of using low doses of methotrexate in ectopic pregnancy patients.

Conflict of interest: Nothing to declare Financial disclosure: Nothing to declare REFERENCES

1. Bonin L, Pedreiro C, Moret $\mathbf{S}$ et al. Predictive factors for the methotrexate treatment outcome in ectopic pregnancy: a comparative study of 400 cases. Eur J Obstet Gynecol Reprod Biol. 2017; 208:23-30.

2. Aydın GA, Özgen $G$ and Yavuz A. Comparative study of low-dose versus standard single-dose methotrexate: A novel approach for medical treatment of ectopic pregnancy $\mathrm{J}$. Obstet. Gynaecol. Res. 2020; 46: 286-292.

3. Perkins KM, Boulet SL, Kissin DM, Jamieson DJ, National ART Surveillance (NASS) Group. Risk of ectopic pregnancy associated with assisted reproductive technology in the United States, 2001-2011. Obstet Gynecol 2015; 125: 70-78.

4. C. Beguin, g. BriChant, L. De LanDsheere, L. teBaChe, s. KarampeLas, L. seiDeL, m. nisoLLe. Use of methotrexate in the treatment of ectopic pregnancies: a retrospective single center study Facts Views Vis Obgyn, 2019, 11 (4): 329335

5. Orozco EM, Sánchez-Durán MA, BelloMuñoz JC et al. Bêta-hCG and prediction of therapeutic success in ectopic pregnancies treated with Methotrexate, results from a prospective observational study. J Matern-Fetal Neo M. 2015; 28:695-699.

6. Tanaka T, Hayashi H, Kutsuzama $\mathbf{T}$ et al. Treatment of interstitial ectopic pregnancy with Methotrexate: report of a successful case. Fertil Steril. 1982; 37:851-852.

7. Barnhart K, Coutifaris C, Esposito M. The pharmacology of methotrexate. Expert Opin Pharmacother 2001; 2: 409-417. 
8. Bachman EA, Barnhart K. Medical management of ectopic pregnancy: A comparison of regimens. Clin Obstet Gynecol 2012; 55: 440-447.

9. Levin G, Dior U, Shushan A et al. Early prediction of the success of Methotrexate treatment by 24-hour pretreatment increment in hCG and day 1-4 change in hCG. Reprod BioMed Online. 2019; 39: 149-154.

10.Stovall TG, Ling FW, Gray LA. Single-dose methotrexate for treatment of ectopic pregnancy. Obstet Gynecol 1991; 77: 754-757.

11.Marret H, Fauconnier A, Dubernard G et al. Overview and guidelines of off-label use of Methotrexate in ectopic pregnancy: report by CNGOF. Eur J Obstet Gynecol Reprod Biol. 2016; 205:105-109.

12.Lesavre M, Curinier S, Capmas $\mathbf{P}$ et al. Utilisation du Methotrexate dans les GEU tubaires. Eur J Obstet Gynecol Reprod Biol. 2015; 44:212-219.

13.Barbier M, Pivano A, Tourette $\mathbf{C}$ et al. Evaluation of a follow-up customized strategy for women treated with methotrexate for an ectopic pregnancy: An observational study. Eur J Obstet Gynecol Reprod Biol. 2019; 236:32-35.
14.Wu J, Ludlow JP, De Vries B, Black K, Beale P. Single-dose methotrexate treatment for ectopic pregnancy and pregnancy of unknown location and progesterone as a predictor of success. Aust N Z J Obstet Gynaecol 2014; 54: 469-474.

15.Potter MB, Lepine LA, Jamieson DJ. Predictors of success with methotrexate treatment of tubal ectopic pregnancy at Grady memorial hospital. Am J Obstet Gynecol 2003; 188: 1192-1194.

16.Nguyen Q, Kapitz M, Downes K, Silva C. Are early human chorionic gonadotropin levels after methotrexate therapy a predictor of response in ectopic pregnancy? Am J Obstet Gynecol 2010; 202: e631-e635.

17.Nowak-Markwitz E, Michalak M, Olejnik M, Spaczynski M. Cut-off value of human chorionic gonadotropin in relation to the number of methotrexate cycles in the successful treatment of ectopic pregnancy. Fertil Steril 2009; 92: 1203-1207.

18.Practice Committee of the American Society for Reproductive Medicine. Medical treatment of ectopic pregnancy: A committee opinion. Fertil Steril 2013; 100: 638-644.

\section{Cite This Article - VANCOUVER Style}

Lashin, M., Alabiad, M., Abdelsalam, W. Values and predictive factors for Success of Methotrexate Therapy in Medical Management of Ectopic Pregnancy. Zagazig University Medical Journal, 2020; (990-996): -. doi: 10.21608/zumj.2020.36662.1902 